\title{
Science and medicine at the millennium
}

A. Kornberg

\begin{abstract}
Correspondence
A. Kornberg

Presented at the XXVI Annual

Meeting of the Brazilian Society

of Biochemistry and Molecular

Biology, Caxambu, MG, Brasil,

May 3-7, 1997.
\end{abstract}

Department of Biochemistry, Stanford University, Beckman Center, Stanford, CA, USA
At the outset, I want to thank Dr. Helena Maria Scofano for inviting me to the 26th Meeting of the Brazilian Society of Biochemistry and Molecular Biology. I am also grateful to Dr. Paulo Mourão making the arrangements for me to come here and to Prof. Jerson Silva for his generous efforts in bringing me from Rio to Caxambu. It is an honor to have this invitation to join you and the opportunity to share my thoughts and feelings on how to advance science in the world and particularly I want to consider how to promote biomedical science in Brazil for the ultimate benefit of Brazil and the rest of the world.

Unfortunately, I know too little about Brazil and Brazilian science to offer specific advice. Yet I know some things that I believe apply to science in general and to Brazil as well. I know that Brazil is potentially a rich country, rich both in physical and human resources. For another, the rapid advances in bioscience technology make it relatively simple for motivated, trained scientists, anywhere, to acquire and assimilate large quantities of sophisticated data in a short time. Finally, science is increasingly a global enterprise. We all share a single language. Because the world profits from scientific progress everywhere, we must all strive to remove the current distinctions between some nations that are producers of basic and technical knowledge and others that are largely consumers of knowledge.

Before we consider the serious problems we face in the pursuit of science, let me reflect first on the status of science and medicine. In my own career in medicine, I have been driven by a deep desire to do science with a conviction that the practice of medicine can ultimately be expressed in a basic, universal language. I believe that by reducing life processes to a molecular basis, we can eventually achieve a more rational and richer appreciation of the living world and our place in it.

I like to use a hunting metaphor to review the progress of medical science in our century. The first two decades of this century were dominated by the microbe hunters who tracked down the microbes responsible for the most dreaded scourges of many centuries: tuberculosis, cholera, diphtheria. There remained terrible diseases - scurvy, pellagra, rickets - for which no microbe could be incriminated. These diseases were caused by the lack of vitamins and so in the 1920s and 1930s the vitamin hunters replaced the microbe hunters.

In the 1940 s and 1950 s, the enzyme hunters discovered the key enzymes in metabolism that use the vitamins to produce the energy for cells to grow and function. Now, these enzyme hunters occupy center stage. We are aware that the enzyme hunters have been replaced in the last two decades by the gene hunters, the genetic engineers who use recombinant DNA technology to identify and clone genes, the blueprints for the enzymes, and introduce them into bacteria and plants to create factories for the massive production of hormones and vaccines for medicine and better crops for agriculture. Biotechnology has become a multi-billion dollar industry.

Almost every day, newspapers report dis- 
coveries by gene hunters of defective genes responsible for one or another disease - diabetes, cystic fibrosis, Huntington's chorea, and amyotrophic lateral sclerosis, as well as genes for predisposition to colon cancer, breast cancer, alcoholism, and mental illness. In view of the progress in science, we can expect that the gene hunters will be replaced in the spotlight. When and by whom? Which kind of hunter will dominate medical science in the last decade of our waning century and into the next millennium? I wonder whether the truly novel hunters who will occupy the spotlight might be the neurobiologists and neurochemists who apply the techniques of the enzyme and gene hunters to the functions of the brain. What to call them? The head hunters.

During this 20th century with its succession of hunters and golden ages in medical science, the current age of gene hunting is undeniably the most golden. We have an inexhaustible supply of genes and simple and efficient techniques to track and capture them. Genetic engineering and related biotechnologies represent the most revolutionary advance in the history of biological and medical science. The term revolutionary is generally overused, but not here. The effects of this advance on medicine, agriculture, and industry have not been exaggerated.

Yet even more revolutionary but generally unnoticed, is a development which, while lacking a name or obvious applications, will inevitably lead to even more remarkable and unanticipated practical applications. I refer to the coalescence, the confluence and the merging of the numerous basic medical sciences into a single, unified discipline which has emerged because it is expressed in a single universal language, the language of chemistry.

Much of life can be understood in rational terms if expressed in the language of chemistry. It is an international language, a language without dialects, a language for all of time, and a language that explains where we came from, what we are, and where the physical world will allow us to go. Chemical language has great esthetic beauty and links the physical sciences to the biological sciences.

Yet when I entered medical school in 1937, the importance of chemistry was hardly noticed. It was a serious question whether genetic phenomena operated by known principles of chemistry and physics. Of course we now understand and examine genetics and heredity in simple chemical terms as DNA. DNA in the chromosomes and genes is easily analyzed, synthesized, and rearranged. Species are modified at will. The cloning of sheep and other mammals should be increasingly easy. It is no longer a question of whether we can sequence the 3 billion base pairs of the human genome, but rather when it will be completed and at what cost.

In science today, we possess phenomenal capacities to acquire and integrate unprecedented quantities of sophisticated data. Yet, in this time of informational plenty, we are beset by serious problems which threaten the foundations of our scientific enterprise. For the sake of brevity, I have selected just three among the many problems which currently concern us in the U.S. and must surely apply elsewhere in the world.

The three problems I want to consider are the anti-science attitudes in society, the consequent lack of support for basic science and the use and possible abuse of advances in science and technology. The first problem is the rising tide of public fear, distrust and rejection of science, both chemical and biological.

Chemistry has had a poor image for some time. "Better things for better living... through chemistry" had been the DuPont slogan for many years. Now the slogan is simply "Better things for better living." The words "through chemistry" were dropped. Last year the largest banks in New York merged: Chase Manhattan and the even larger Chemical 
Bank. Not surprisingly, the new giant bank is simply the Chase Manhattan. There is no "chemical" in its name. In fact, the only times we hear something good said of chemistry these days are references, as in newspaper articles, to the good chemistry of a winning football team, or a profitable corporation.

The image of biologists has not been doing well either. Hollywood has chosen them as their villains in recent films. Lacking communists as culprits, and squeamish about racial bashing, some hit movies have demonized doctors and scientists.

And then there is the disillusionment with the failure of science to cure the ills of society. Vaclav Havel, the celebrated Czech author and statesman, and his followers often put the blame on science.

As a result of an uninformed or misinformed public, we have the second problem, the lack of adequate financial support for science. It is a poverty worsened by severe pressures to engage in targeted research such as the treatment of breast cancer and AIDS or by incentives offered to develop technologies to improve the economy.

I like to tell the story of the surgeon who was jogging around a lake and spotted a man drowning. He dove in, dragged the victim ashore, and resuscitated him. He resumed his jogging, only to see two more men drown-

ing. He also saw a colleague, a professor of biochemistry nearby, absorbed in thought. He called to him to go after one while he went after the other. When the biochemist was slow to respond, he shouted: "Why aren't you doing something?" The biochemist said: "I am doing something. I'm desperately trying to figure out who's throwing all these people in the lake."

This parable is not intended to convey a lack of regard for fundamental issues among clinicians nor a callousness among scientists. Rather, it portrays the reality that a serious problem, a war on disease, must be fought on several fronts. Some contribute their special skills to the distressed individual while others try to gain the broad knowledge base necessary to cope with present and future enemies.

The best plan for combating a disease has been, over many decades, no plan at all. For lack of essential knowledge, timetables for assaults on particular disease targets have had little meaning. Nor could we have anticipated the confrontations with novel diseases, such as AIDS, Legionnaires' disease, septic shock and drug-resistant tuberculosis.

A well-designed plan, by its very nature, cannot lay the groundwork for the utterly novel techniques that make possible major transformations in the acquisition and application of knowledge. The success of the National Institutes of Health (the NIH) in the U.S. has changed the face of medicine in the post-World War II period. It was not planned. This extraordinary success is owed to channeling a major fraction of the budgets of the Heart, Cancer, Arthritis, and twenty other disease institutes to basic research. Had this money been spent instead in palliating these various diseases, the current advances in preventing and curing them would have been squandered. How tragic that the NIH, with a budget for basic research of less than $1 \%$ of the health care dollar spent in the U.S. and the best investment we can make to improve the quality of medicine, is now faced with devastating cuts for research and training.

The breakthrough of recombinant DNA and genetic engineering was based on the discoveries of enzymes that make, break and seal DNA. All these basic advances were made in academic laboratories built and supported almost entirely by funds from the NIH. For thirty years, my research on the biosynthesis of the building blocks of nucleic acids, their assembly in DNA replication and the training of over a hundred young scientists, was funded with many millions of dollars without any promise or expectation that this research would lead to marketable products or procedures. No industrial organ- 
ization had or would ever have the resources or disposition to invest in such long-range, apparently impractical programs. We carried out these studies to satisfy our curiosity. Yet to my great pleasure, such studies of the replication, repair and rearrangements of DNA have had many practical benefits.

For example, the pathways of assembling the building blocks of nucleic acids from simple nutrients and their subsequent assembly into RNA and DNA have been the basis for the design of most drugs used today in the chemotherapy of cancer, AIDS, herpes and the treatment of autoimmune diseases. This knowledge is also crucial to understanding the repair of DNA, so important in the aging process, for understanding mutations and the origin of some cancers.

It may seem unreasonable and impractical - we use the word counterintuitive - to most people, including scientists, that the solution of an urgent problem, such as the cure of a disease, will come from asking unrelated questions in basic biology or chemistry. Yet, the pursuit of understanding about the basic facts of nature has proven throughout the history of medical science to be the most practical, the most cost-effective route to successful drugs and devices.

Investigations that seemed totally irrelevant to any practical objective have yielded most of the major discoveries of medicine $\mathrm{X}$-rays were discovered by a physicist observing electric discharges in vacuum tubes; penicillin came from enzyme studies of bacterial lysis; the polio vaccine came from the engineering made possible by basic studies on how to grow animal cells in the test tube. As I have mentioned, genetic engineering and recombinant DNA depended on reagents which were developed in exploring DNA biochemistry. All these discoveries have come from the pursuit of understanding about questions in physics, chemistry and biology, unrelated at the outset to a specific medical or practical problem.

We have a saying: "Necessity is the mother of invention." But this is usually wrong. Generally, the reverse has proven to be true: Invention is the mother of necessity. Inventions only later become necessities!

Time and again, inventors created things that had to wait many years to be recognized for their practical value. Nobody really needed the airplane, the FM radio, television, the transistor, or the quantum mechanics that led to the transistor. FAX machines were invented 30 years ago, but it took a deteriorated postal service among other factors to make them the necessities they are today.

The lessons to be learned from this history should be crystal clear. It is crucial for a society, a culture, a company, a university, to understand the nature of the creative process and to provide for its support. The future is invented, not predicted. No matter how counterintuitive it may seem, basic research will remain the lifeline of practical advances in medicine, just as pioneering inventions will be the source of industrial strength.

How can we convince people to support basic research? Perhaps the analogy of rearing a child would help. We accept the uselessness of an infant, and the cost of its education and support for more than twenty years in the hope of producing a useful citizen. In the same vein, we need to explain that basic research also follows a tortuous and uncertain route. It is an investment that needs to be supported for a long time to produce the practical advances for medicine and industry.

Of course it is important that basic discoveries be promptly and wisely applied to solve practical problems. The recent applications of biotechnology to medicine have given us major insights into diabetes, cancer and other metabolic diseases. Will these approaches and techniques be equally effective when applied to the human brain and behavior? I am sure they will. After all, the mind is matter and only matter. The same chemical language that describes the func- 
tions of the heart and liver surely applies to the operations of the brain.

The overriding issue in biomedical science as I see it, throughout the industrial world, is how to give our abundant scientific talent the resources to exploit the extraordinary new technologies to advance knowledge. Currently, a pervasive mood in the U.S. among productive biomedical scientists makes them fear for continued grant support, persuades them to choose safe and practical projects over the untried and adventurous, and tempts their interest in commercial ventures. This is clearly a state that discourages young people from entering science and drives others to abandon science for business, law and medical practice.

As scientists, we are urged to make the case for support of biomedical research with their fellow citizens, to be friend-raisers in the community, and to persuade their legislators to increase the federal budget for sciences. Then we are criticized for doing none of these things. Our friends in the community and in the legislature fail to realize that scientists, as a group, are self-selected for their interest in molecules and cells and their disinterest in people and politics. Unlike virtually every other segment of society doctors, lawyers, businessmen, farmers - scientists fail individually and collectively to lobby for their cause.

The most prestigious of our scientific societies in the U.S., the National Academy of Sciences, through its National Research Council, makes awesome contributions of factual information from highway construction to child care. Yet, it has as a matter of policy refrained from efforts to maintain, let alone increase federal support for basic research. The Academy has been fearful of appearing political. As for the lobbying efforts of the major scientific societies, they have been amateurish and grossly inadequate. Pleadings by the Cancer Society, Heart Society, and fifty other disease societies, universities, medical schools and concerned indi- viduals are not heard because they are splintered, divisive, incoherent and unfocused constituencies. They fail in informing our administrators and legislators of the value of basic biomedical research.

For its long-term support, we need to convey this message. "If you think research expensive try disease." We need to inform our fellow citizens, especially at this time of severe budgetary restraints, and in competition with imperative and urgent social programs, to examine the history of medical science. The major advances in diagnosis, prevention of and treatment of disease were based on the pursuit for understanding of nature by biologists, chemists and physicists, pursuits unrelated to the ultimate application of this basic knowledge to the development of vaccines, drugs and devices.

I am currently making a proposal to obtain long-term federal support in the U.S. for basic biomedical research. It is novel in its grand scale and the direct involvement of all biomedical scientists. I see nothing wrong, base or narrow in organizing and operating a national organization of scientists to promote health science. I believe that with proper leadership, such an organization can enroll a sufficient number of bioscience investigators whose modest annual dues, combined with contributions from universities, pharmaceutical companies and private donors, could maintain an annual budget that could support a staff of 20 or more people in Washington skilled in attracting media attention, informing Congress and the public in every one of the 435 legislative districts in the country. I believe that scientists will respond eagerly to requests to present their research and describe its significance to benevolent groups in their communities. So, for once, scientists will be seen actively promoting science for the public welfare and be relieved of criticisms of indifference and selfishness. And for once there will be one sustained, reasoned voice making the case for biomedical research support rather than 
the present babble of an undisciplined chorus.

Having considered the serious problems of the public understanding and support of basic biomedical research in the U.S., despite all its size, wealth, infrastructure and success of biomedical science, I am aware of how much more difficult these problems must be in Brazil. How can scientists in Brazil, with so much less support and public understanding, hope to achieve success in severe competition with scientists in the U.S., Europe and Japan?

In Brazil, with so many urgent problems of human nutrition and disease, with limited resources in biotechnology, and with frustrating obstacles of inflation, poor compensation and incredible bureaucratic roadblocks, how reasonable is it for scientists to expect the long-term public support for advanced training and basic research?

These are all very serious problems and I must surely have failed to mention many more that you face here every day, even under the best conditions, in your struggles to do science. Beyond that, all of us in science, exploring at the frontiers of science, are engaged in struggles with nature itself and as we delve deeper we face increasing complexities of molecules, cells and systems. And should we succeed on occasion in making some progress, despite all the hardships and confusion, we then face the threat that some others somewhere in the world have already made the discovery or will be better equipped to exploit our discovery when we publish it.

Despite all these difficulties, I believe that the proposal I am making for the longterm, federal support of basic biomedical research in the U.S. has some relevance to Brazil. Let me venture several specific suggestions.

1) Biomedical scientists should develop a national organization with the stated purpose of promoting research for the nation's health. Workers should organize in unions to promote their own needs and rights. How much more persuasive it would be for organized scientists to speak with one voice to the central government and local communities to promote the national welfare, to declare that basic biomedical research is essential for the health and the economy of the nation.

2) Although Brazil is now a net consumer of new knowledge, it is essential that Brazilian scientists be producers of knowledge, so that they can provide prompt and effective use of new knowledge from abroad.

3) Brazilian biomedical science leads the world in studies of Chagas' disease. Yet, as with other serious and complex diseases, such as cancer, AIDS and malaria, intense efforts focused on a disease target are invariably limited for lack of fundamental understanding of life processes. Such basic studies here in Brazil would complement the more directed studies on Chagas' disease in powerful and unanticipated ways.

4) Finally, Brazilian scientists and institutions must greatly increase international exchanges through fellowship training and research collaborations with advanced institutions, particularly in our own hemisphere. In the U.S. we now support enormous numbers of students and fellows from Asia China, Taiwan, Korea, Vietnam, Japan and India - but we have very few from Brazil and Latin America. We need them and would welcome them.

Let me finally consider very briefly the third problem I posed: the uses and possible abuses of advances in biomedical science and technology. Now and for decades into the next century, we will be confronted in medicine between the need to advance the scientific base and the art to apply it. There can be no argument that knowledge beats ignorance. By having identified the genetic lesions responsible for sickle-cell anemia, thalassemia, cystic fibrosis, Huntington's disease and Tay-Sachs disease, we have vastly improved our capacity to avoid them. 
There can be no argument that we must continue to do hard science, to understand mechanisms and develop technologies in order to monitor and sustain health and to combat disease. Equally difficult will be our capacity to cope with the avalanche of data and technologies that emerge from our scientific enterprise.

In the race of expanding technologies, will we urge annual tests to monitor every genetic predisposition: to diabetes, atherosclerosis, hypertension, cancer and twenty other diseases? Will we prescribe more vaccines, pills, and injections? Will we order endless analyses? If we do, we will do harm. We will cultivate a nation of unhappy people, insecure in their jobs, unable to get insurance, and we will exhaust our economic resources.

In the course of this talk, I have focused on three of the major problems that confront us in science: the anti-science forces in society, the lack of support of basic research and the uses and possible abuses of science and technology. I could add more problems to this list. And you could add many more that you face here in Brazil. Despite all these difficulties and discouragements, do I recommend a career in biomedical science to all of you gathered here and to your children, and to my grandchildren at home? Emphatically I do.

I want to recognize what deserves the most emphasis and what unites us all. It is our unconflicted and overriding devotion to the culture of science. We must make it clear to the public that although science is great, scientists are still people. As people, they are no different from others: dentists, lawyers, artists, businessmen. Scientists are just as prey to the human failings of arrogance, greed, dishonesty and psychopathy. What does set them apart from others is the discipline of science, a practice that demands exact and objective descriptions of progress, evidence that can be verified or denied by others.
It is the discipline of science that enables all of us ordinary people, whether we be chemists, biologists or physicians, to go about doing the ordinary things, which, when assembled, reveal the extraordinary intricacies and awesome beauties of nature. Science not only permits us to contribute to grand enterprises, but also offers changing and endless frontiers for exploration.

I have been very fortunate in my career to have had so many opportunities for exploration. For forty years, I pursued a wish to identify the building blocks of coenzymes and nucleic acids and to understand how they are made and assembled into RNA and DNA. Five years ago, I stopped working on DNA replication and began to explore another polymer, simple inorganic, a polymer that was likely active on earth early in prebiotic evolution and is now found in every cell in nature - bacterial, fungal, plant and animal. It is inorganic poly $\mathrm{P}$, chains of hundreds of phosphate residues, linked by the high-energy, anhydride bonds found in ATP from which it is made enzymatically. Because the polymer is so ancient and apparently functionless in its current cellular locations, it has been regarded as a molecular fossil.

We have developed rapid, sensitive and definitive enzymatic methods to measure inorganic poly $\mathrm{P}$ and have used reverse genetics to probe its physiologic functions. One of the most intriguing in our current studies in E. coli is finding that poly $\mathrm{P}$ is essential for responses to stress and for survival in the stationary phase. In recent seminars I have used the title: "Inorganic Poly P: A Molecular Fossil Come to Life." I had been tempted to use an even more mysterious title: "A Fossil Come to Life" but then I was worried that people would expect to hear a personal memoir.

With regard to how we do bioscience research these days, have the computer revolution and other advanced technologies altered the way we do research? Can research 
now be engineered and pursued by formula? Not yet. The technical tools are indispensable, but the practice of science remains in essence an art form and its province is nature. In the practice of science, as in art, what is absolutely essential is the spirit, motivation, enthusiasm, and the desire to reveal some facet of nature, no matter how small, that adds to the awesome tapestry of the natural world.

Sir Karl Popper, an eminent philosopher of science and society, who died last year in London, said that "next to music and art, science is the greatest, most beautiful and most enlightening achievement of the human spirit." I would place science first.

We probe the inexhaustible mysteries of nature from a variety of directions, and with different intensities and styles. These probings are determined by our emotions, our moods and our cultural heritage, much as these influence the artist. The major discoveries in science are more often intuitive or serendipitous than the result of logical analysis.

The machines we use produce images and compositions of objective precision. But this should not obscure the fact that we use these machines as tools, with tastes as distinctive as those that painters use their palettes, composers their notes, and authors their words in creating their images of nature. Seneca, the great Roman statesman and philosopher, once said: "All art is but imitation of nature." What we try to do in science is to get ever closer to nature. In the art of medicine, we try to find for the individual a harmonious niche in nature.

I conclude by thanking you again for the privilege of being with you and sharing my thoughts and feelings about how to advance science in the world and particularly in Brazil. 